\title{
Campanha Nacional de Prevenção a Quedas de Idosos Dia 27 de setembro: Dia de atendimento ao idoso com tontura
}

\section{Fernando F. Ganança ${ }^{1}$, Raquel Mezzalira ${ }^{2}$, Oswaldo Laércio M. Cruz}

No dia 27 de setembro, Dia Nacional do Idoso, a SBO realizará mais uma etapa da Campanha Nacional de Prevenção a Quedas de Idosos.

Muitas razões justificaram esta iniciativa da SBO. As quedas constituem a $6^{\mathrm{a}}$ causa de óbito em pessoas com mais de 65 anos $^{1}$. Estima-se que 30\% das pessoas acima dessa faixa etária sofram quedas ao menos uma vez por $a_{n o}^{2}$, sendo essas responsáveis por $70 \%$ das mortes acidentais em pessoas com 75 anos ou mais ${ }^{3}$.

Essas estimativas apontam índices alarmantes já que, em 2025, nosso país poderá contar com 31,8 milhões de habitantes com 60 anos ou mais, e ocupará o $6^{\circ}$ lugar no mundo na população de idosos ${ }^{4}$

As doenças vestibulares assumem particular importância neste contexto, pois o aumento da idade é diretamente proporcional à presença de diferentes sintomas vestibulares e manifestações clínicas tais como: vertigem e outras tonturas, alterações do equilíbrio corporal, restrição de movimentação, insegurança física e psíquica na locomoção e distúrbios da marcha e queda ${ }^{5,6}$. Essas alterações do aparelho vestibular elevam o número de quedas em pacientes idosos em relação aos idosos da comunidade em geral ${ }^{7}$.

Com base nestes dados, a SBO lançou no dia 27 de setembro de 2005 a Campanha Nacional de Prevenção a Quedas de Idosos visando orientar a população sobre o risco de queda e sua prevenção. Até agora vínhamos fazendo um trabalho de conscientização para que as pessoas pudessem identificar e eliminar os principais fatores de risco. Essa medida é fundamental uma vez que cerca de $60 \%$ das quedas ocorrem em casa durante as atividades do dia-a-dia, sendo que $25 \%$ delas são resultantes de "perigos domésticos" como pisos escorregadios, pouca luminosidade e disposição inadequada de móveis. O trajeto quartobanheiro, principalmente à noite, é considerado o de maior risco na moradia. Enquanto alguns fatores de risco para a queda não podem ser modificados, como o envelhecimento, outros podem ser facilmente eliminados ou reduzidos.

Agora, com o "Dia de atendimento ao idoso com tontura", a SBO dará início à segunda fase da Campanha. Este evento será realizado no dia 27 de setembro (Dia do Idoso) e está organizado para colher dados epidemiológicos para avaliar ocorrência de afecções vestibulares, quedas no passado, risco de quedas no futuro, entre outros dados sócio-demográficos e clínicos. As informações clínicas e sócio-demográficas serão coletadas por intermédio de protocolo de anamnese elaborado pela SBO, que será disponibilizado oportunamente no site www.sbotologia. com.br/campanhaquedas.

Além do atendimento inicial ao paciente e coleta de dados, a iniciativa desta ação visa também continuar o trabalho de aumentar o conhecimento do público em geral sobre os problemas relacionados às quedas na terceira idade, incentivar a procura de atendimento otorrinolaringológico pelos idosos que apresentam tontura e/ou histórico de quedas, orientando no encaminhamento para investigação diagnóstica e tratamento dos possíveis distúrbios vestibulares, além de fornecer informações sobre prevenção. A distribuição de informações sobre tontura e quedas, por meio de material elaborado pela SBO, também estará disponível.

Esta iniciativa, de abrangência nacional, só será possível se contarmos com a participação de todos os serviços de Otorrinolaringologia credenciados pela Associação Brasileira de Otorrinolaringologia e Cirurgia Cérvico-Facial (ABORL) e dos associados da ABORL. O convite para participação será feito por meio de mensagem eletrônica (e-mail) direcionada aos endereços que constarem no cadastro da ABORL.

Aqueles que já se interessarem em participar desta campanha poderão se inscrever pelo site http://www.sbotologia. com.br/campanhaquedas/seu-cadastro.asp e definir o número de pacientes para este primeiro atendimento até o dia 30 de maio de 2008. Ressalta-se que este atendimento não deverá gerar custos ao paciente assistido, isto é, todo o atendimento será gratuito. Devemos ressaltar também que essa primeira avaliação deverá indicar alguns pacientes portadores de doença vestibular. Assim, os serviços e colegas que participarem deste primeiro atendimento deverão assumir o acompanhamento clínico posterior (investigação diagnóstica e tratamento) dos idosos que apresentarem afecções vestibulares.

A divulgação da campanha será realizada pela SBO, por meio de mídia especializada (rádio, jornal e televisão), mas o próprio associado ou serviço credenciado em sua comunidade poderá ajudar muito nesta divulgação.

Após o evento, a SBO pretende coletar todas as informações obtidas para análise e posterior divulgação seguindo o modelo de estudo clínico epidemiológico multicêntrico.

Para maiores informações acesse o site da SBO.

Para que esta campanha tenha sucesso, a SBO conta com a sua participação.

\section{REFERÊNCIAS BIBLIOGRÁFICAS}

1. Baraff LJ, Della Penna R, Willians N. Practice guideline for the ED Management of falls in community - dwelling elderly persons. Ann Emerg Med 1997; 30: 480-92.

2. Campbell AJ, Borrie MJ, Spears GF. Risk factors for falls in a communitybased prospective study of people 70 years and older. J Gerontology 1989; 44: M112-7.

3. Fuller GF. Problem-oriented diagnosis: falls in the elderly. Am Fan Physiciam 2000; 61: 2159-68

4. Veras RP. País jovem com cabelos brancos. Rio de Janeiro: Relume \& Dumara, 1994

5.Ganança MM, Caovilla HH. Desequilíbrio e reequilíbrio. In: Ganança MM. Vertigem tem cura? São Paulo: Lemos Editorial 1998. p.13-9.

6. Gazzola JM, Aratani MC, Perracini MR, Ganança MM, Ganança FF. Circunstâncias e Conseqüências de quedas em idosos com vestibulopatia crônica. Rev Bras Otorrinolaringol.,2006;72:388-93.

7. Herdman SJ, Baltt P, Schubert MC, Tusa RJ. Falls in patients with vestibular deficits. Am J Otol 2000; 21: 847-51.

${ }^{1}$ Professor Adjunto da Disciplina de Otologia/Otoneurologia do Departamento de Otorrinolaringologia e Cirurgia de Cabeça e Pescoço da Universidade Federal de São Paulo/Escola Paulista de Medicina. Coordenador da Campanha de Prevenção às Quedas na Terceira Idade.

2 Mestre em Ciências Médicas pela Faculdade de Medicina da Universidade Estadual de Campinas (UNICAMP) e médica do Setor de Otoneurologia da Disciplina de Otorrinolaringologia e Cirurgia de Cabeça e Pescoço da UNICAMP. Coordenadora da Campanha de Prevenção às Quedas na Terceira Idade.

${ }^{3}$ Professor Livre-Docente em Otorrinolaringologia pela Universidade de São Paulo, Professor Afiliado, Chefe da Disciplina de Otologia/Otoneurologia do Departamento de Otorrinolaringologia e Cirurgia de Cabeça e Pescoço da Universidade Federal de São Paulo / Escola Paulista de Medicina. Presidente da Sociedade Brasileira de Otologia. 